\title{
The Physical Activity, Nutrition and Obesity Research Group: fostering population health research in NSW
}

\author{
Andrew J. Milat ${ }^{\mathrm{A}, \mathrm{C}}$, Lesley King ${ }^{\mathrm{B}}$ and \\ Adrian Bauman ${ }^{\mathrm{B}}$ \\ ${ }^{\mathrm{A}}$ The Sax Institute (formerly Centre for Health Advancement, \\ NSW Department of Health) \\ ${ }^{\mathrm{B}}$ Physical Activity, Nutrition and Obesity Research Group, \\ The University of Sydney \\ ${ }^{\mathrm{C}}$ Corresponding author.Email: andrew.milat@saxinstitute.org.au
}

The requirements of policy makers for contextually relevant evidence are increasingly documented and understood. ${ }^{1,2}$ In response, there have been significant recent international and Australian initiatives to facilitate closer links between policy makers and researchers to address questions of policy relevance. ${ }^{3-5}$ The gap between researchers and policy makers has been well described by Lomas, who noted that: ' ...efforts by researchers and by decision makers seem to proceed largely independently. Both have their own (often misplaced) ideas about the other's environment. Opportunities for ongoing exchange and communication are few...'. 6 One way to bridge this structural and communication gap is to develop formal collaborative mechanisms between researchers and policy makers, such as the establishment of university-based research centres. ${ }^{7}$

\section{The role of the Physical Activity, Nutrition and} Obesity Research Group as a university-based research centre

The New South Wales (NSW) Department of Health has arguably led the way in Australia with its commitment to funding university-based research groups to inform public health efforts across a range of issues including drug and alcohol, HIV/AIDS, injury prevention, immunisation, physical activity, nutrition and obesity prevention. The development of a body of policy-relevant research that is rapidly applied to policy and practice is particularly important for primary prevention of chronic disease, as there continues to be limited high quality and appropriate evidence of effective and sustainable interventions. ${ }^{8}$ Over the past decade, this funding has, at different times, supported the NSW Centre for Overweight and Obesity, the NSW Centre for Physical Activity and Health, and the NSW Centre for Public Health Nutrition. A review of these centres in 2007 concluded that they had made important contributions to health behaviour surveillance, determinants and intervention research, and ultimately resulted in greater collaboration between policy makers and researchers. ${ }^{9}$ The review also recommended the formation of a larger, single research group across these interconnected health issues with longer term funding.

After an open tender process in June 2008, the NSW Department of Health committed $\$ 4.4$ million over 5 years to the School of Public Health at the University of Sydney to establish the Physical Activity, Nutrition and Obesity Research Group (PANORG). Similar to its predecessors, the work of PANORG is organised according to the following four key building blocks for generating and reviewing public health evidence:

- population monitoring

- determinants and environments

- intervention research

- measurement tools.

Illustrative examples of PANORG's work in these areas are outlined in Table 1.

In contrast to investigator-driven research groups, PANORG has clear arrangements for regular and frequent communication and exchange with policy makers, including:

- a specified program of policy-relevant research negotiated between the research group and funders

- two-way communication systems, with a mix of formal (e.g. quarterly reports) and informal exchanges

- a purposive, planned approach to the dissemination of research results and products to relevant end user groups.

This systematic and purposeful involvement of both parties in policy making and research development processes contributes to better population health research, ensuring that research projects are policy relevant and timely, whilst achieving excellent academic quality and publication in peer-reviewed journals. An example of purposeful collaborative involvement has been the development and implementation of the 2010 NSW Schools Physical Activity and Nutrition Survey, the fourth in Australia's longest running series of 
Table 1. Examples of Physical Activity, Nutrition and Obesity Research Group research across key building blocks for evidence creation

\begin{tabular}{llll}
\hline Population monitoring & $\begin{array}{l}\text { Determinants and } \\
\text { environments }\end{array}$ & Intervention research & Measurement tools \\
\hline $\begin{array}{l}\text { NSW Schools Physical } \\
\text { Activity and Nutrition } \\
\text { Survey (SPANS) } 2010\end{array}$ & $\begin{array}{l}\text { Children's exposure to } \\
\text { food marketing }\end{array}$ & $\begin{array}{l}\text { Evaluation of Phase 1 of NSW } \\
\text { Munch and Move Program }\end{array}$ & $\begin{array}{l}\text { NSW Overweight and Obesity } \\
\text { Monitoring Framework }\end{array}$ \\
$\begin{array}{l}\text { Secondary analyses of } \\
\text { in preschools }\end{array}$ & $\begin{array}{l}\text { children's sedentary } \\
\text { behaviours and fitness }\end{array}$ & $\begin{array}{l}\text { Good for Kids Good for Life } \\
\text { child obesity prevention }\end{array}$ & $\begin{array}{l}\text { An inventory of physical activity } \\
\text { measurement tools for field } \\
\text { pealth Survey and }\end{array}$ \\
$\begin{array}{l}\text { School Students Health } \\
\text { Behaviours Survey }\end{array}$ & & $\begin{array}{l}\text { Collaboration with area health } \\
\text { servaluation }\end{array}$ & $\begin{array}{l}\text { Epidemiological work around } \\
\text { streamlining physical activity } \\
\text { surveillance tools for population } \\
\text { monitoring }\end{array}$ \\
\hline
\end{tabular}

children's physical activity and nutrition surveys. The Department managed the stakeholder engagement that informed the development of the survey, while PANORG oversaw survey fieldwork, data analysis and reporting.

This collaboration also extends to PANORG regularly providing expert and technical advice to the Centre for Health Advancement at the NSW Department of Health regarding health issue priorities, strategic policy and program directions and evaluations. Another recent example was the provision of evidence and technical advice that has shaped the development of NSW Implementation Plans and Evaluation and Monitoring frameworks for the Council of Australian Governments' National Partnership Agreement on Preventative Health. This level of access was only possible due to the close and ongoing relationship between PANORG and the Department that is protected by mutually agreed contractual obligations. In addition, PANORG collaborates with local area health services' health promotion strategic planning and research and evaluation activities.

\section{Conclusion}

As a government funded university research group, PANORG plays an active role in bridging the gap between evidence, policy and practice in NSW in the areas of physical activity, nutrition and obesity prevention. Frequent communication and ongoing collaboration between policy makers and researchers contributes to better population health research outcomes in NSW.

\section{Acknowledgments}

The authors would like to thank NSW Department of Health and PANORG staff, both past and present, who work tirelessly to close the gap between research and practice.

\section{References}

1. Campbell DM, Redman S, Jorm L, Cooke M, Zwi AB, Rychetnik L. Increasing the use of evidence in health policy: practice and views of policy makers and researchers. Aust New Zealand Health Policy 2009; 6: 21. doi:10.1186/17438462-6-21

2. Bowen S, Zwi A, Sainsbury P. What evidence informs government population health policy? Lessons from early childhood intervention policy in Australia. NSW Public Health Bull 2005; 16(11-12): 180-4.

3. National Health and Medical Research Council. National Health and Medical Research Council Strategic Plan 2007-2009. Canberra: NHMRC; 2007.

4. NSW Department of Health. NSW Health Promotion Demonstration Research Grants Scheme Funding Priorities. Available from: http://www.health.nsw.gov.au/publichealth/ healthpromotion/grants/index.asp (Cited 24 May 2010.)

5. Canadian Institutes of Health Research. Health Research Roadmap: Creating innovative research for better health and health care CIHR Strategic Plan: 2009/10-2013/14. Ottawa: CIHR; 2009.

6. Lomas J. Research and evidence-based decision making. Aust NZJ Public Health 1997; 21: 439-41. doi:10.1111/j.1467842X.1997.tb01730.x

7. Langille LL, Crowell SJ, Lyon REF. Six essential roles of health promotion research centres: the Atlantic Canada experience. Health Promot Int 2009; 24(1): 78-87. doi:10.1093/heapro/ dap001

8. World Health Organization. Interventions on diet and physical activity: what works. Summary report. Geneva: WHO; 2009.

9. Scott J, Bowen S. Review of NSW Health funded: Centre for Overweight and Obesity (COO), Centre for Physical Activity (CPAH), and Centre for Public Health Nutrition (CPHN). Unpublished Report; 2007. 